the $6 \mathrm{MW}$ (OR of 1.63), and at 14 weeks on the $8 \mathrm{MW}$ and the STS (OR of 2.0). Conclusions: PRF in MS patients appears to enhance the benefit of active enabled motor training and to better sustain it over the following 8 weeks.

\section{NeURology (Neurocritical Care/Neuro Trauma)}

\section{P.044}

\section{Time to loss of neurological function after circulatory} arrest: a scoping review

PM Pana (Montreal)*L Hornby (Ottawa) S Shemie (Montreal) J Teitelbaum (Montreal) S Dhanani (Ottawa)

doi: $10.1017 /$ cjn.2015.154

Background: Donation after circulatory death (DCD) can reduce organ transplant waiting times. When defining death using circulatory criteria, brain function is usually not assessed. Residual brain function and the state of consciousness at the time of circulatory arrest is unknown. We have an ethical responsibility to ensure the donor is free of pain and psychological distress. Methods: We performed a scoping review of the literature to determine the time intervals associated with the loss brain function after circulatory arrest. Results: A total of 1133 articles were reviewed and 38 were included in the review. In humans, 8 studies showed loss of EEG activity under 30 seconds. Four studies revealed loss of EEG between 39.6 and 66 seconds. Clinically, loss of consciousness was shown to occur between 4 and 21 seconds. In animals, 13 studies also revealed loss of EEG under 30 seconds. In four other animal studies, EEG was lost between 37 and 120 seconds. Conclusion: The time required to lose brain function varied according to clinical context and method by which this function is measured. Existing literature is scarce and limited to observational studies and case reports.

\section{P.045}

\section{NMDA-receptor encephalitis: An unsual case of refractory} status epilepticus

$S$ Lapointe (Montréal)* C Legault (Montreal) P Giacomini (Montreal) $R$ La Piana (Montreal) J Teitelbaum (Montreal) D Tampieri (Montreal) A Romano (Montreal)

doi: $10.1017 / \operatorname{cjn} .2015 .155$

Objective: Case report of NMDA receptor encephalitis in a young man with early refractory status epilepticus and atypical radiological findings. Background: Anti-NMDA receptor encephalitis is an autoimmune disorder due to antibodies to the NR1-NR2B heterodimer of NMDA receptor. On imaging, it typically presents with T2 hyperintensities in mesio-temporal lobes, cerebral cortex and basal ganglia. We present a case with a dramatic clinical evolution and novel imaging findings. Design/Methods: Case report and review of imaging. Results: 29-year-old male presented with mood disturbance followed by partial-complex seizures, facial dyskinesia and choreoathetotic movements. Initial MRI showed subtle T2-hyperintensities in mesio-temporal lobes. Diagnosis of NMDA-receptor encephalitis was confirmed after CSF antibody detection. Prior to diagnostic confirmation, he developed refractory status epilepticus, and concomitant signs of herniation. A repeated MRI showed increased T2-hyperintensities of thalami and mesencephalon, with cerebellar involvement and transtentorial/foraminal herniation. Restricted diffusion was documented in the cerebellar cortex/thalami/putamina and caudate. IV corticosteroids and hypertonic fluid reversed herniation, and halted the seizures. Conclusions: To our knoweldge, we report the first case report of uncal and tonsillar herniation in NMDA-r encephalitis secondary to atypical, predominant cerebellar involvement. This case highlights life-threatening manifestation that physicians might encounter, and a possible role for high dose IV corticosteroids as an adjunct treatment for brain edema and seizures.

\section{Neurology (NeURomuscular)}

\section{P.046}

Disparate production of IL-27 in CSF and plasma of Guillain-Barré syndrome and other neurological disorders

$Y$ Wang (Changchun) Y Zhu (Changchun) W Zhang (Changchun) M Liu (Changchun) G Li (Changchun) H Zhang (Changchun)*

doi: 10.1017/cjn.2015.156

Background: IL-27 acts as a 'master regulator' in modulating inflammation and was responsible for a number of autoimmune diseases. However, the role of IL-27 was not addressed in Guillain-Barré syndrome (GBS). Methods: Sixty-five subjects including 19 with GBS, 7 with encephalitis or meningitis, 23 with multiple sclerosis or neuromyelitis optica as well as 11 with other non-inflammatory neurological disorders were enrolled. ELISA was used to detect the concentrations of IL-27 in paired samples of cerebrospinal fluid and plasma. Results: The mean concentration of IL-27 in GBS patients was significantly lower than in other neurological disorders both in CSF and in plasma (all $\mathrm{p}<0.05$ ). GBS patients with cranial involvement, decreased reflexes, hypaesthesia, autonomic nerve dysfunction, MRC score $<30$ are inclined to have a lower CSF IL-27 level than patients without these symptoms $(182 \mathrm{pg} / \mathrm{ml}, 181 \mathrm{pg} / \mathrm{ml}, 185 \mathrm{pg} /$ $\mathrm{ml}, 185 \mathrm{pg} / \mathrm{ml}, 194 \mathrm{pg} / \mathrm{ml}$ vs $211 \mathrm{pg} / \mathrm{ml}, 205 \mathrm{pg} / \mathrm{ml}, 202 \mathrm{pg} / \mathrm{ml}, 198$ $\mathrm{pg} / \mathrm{ml}, 199 \mathrm{pg} / \mathrm{ml}$, respectively). Similar results were noted in plasma except for cranial involvement. Conclusions: Production of IL-27 was disparate between GBS and other neurological diseases and a significantly lower level of IL-27 was observed in GBS patients, indicative of an anti-inflammatory role of IL-27 in GBS.

\section{P.047}

Enteral nutrition in amyotrophic lateral sclerosis (ALS): Canadian practices

T Benstead (Halifax)*C Jackson-Tarlton (Halifax)* D Leddin (Halifax)

doi: $10.1017 / \operatorname{cjn} .2015 .157$

Background: Dysphagia from ALS may be treated by enteral nutrition; however criteria for timing of feeding tube placement has not been well studied. The aim of this project was to better understand the practice of enteral nutrition management within Canadian ALS clinics. Methods: ALS clinics were asked if they had written guidelines for timing of PEG insertion and if not, what criteria they 